\title{
A PROTEÇÃO DO DIREITO À VIDA NAS CONSTITUIÇÕES REPUBLICANAS BRASILEIRAS
}

THE PROTECTION OF RIGHT TO LIFE IN THE BRAZILIAN'S REPUBLICANS

CONSTITUCIONS

Francisco llídio Ferreira ROCHA ${ }^{1}$

ISSUE DOI: $10.21207 / 1983.4225 .858$

\begin{abstract}
RESUMO
O presente artigo tem como escopo a análise do direito à vida durante a sucessão histórica de Constituições brasileiras que se apresentaram durante o período republicano. Através de um estudo histórico e dogmático-jurídico, pretende-se investigar o desenrolar da tutela constitucional da vida humana durante os sucessivos momentos da história nacional, compreendendo-a em seu contexto temporal e, estabelecendo distinções e interrelações, clarificando o alcance normativo o direito à vida constitucionalmente assegurado na Constituição Federal de 1988.
\end{abstract}

Palavras-chave: Direito à vida, Direitos concernentes à vida, Direito à segurança individual. Constituições republicanas.

\section{ABSTRACT}

The present article has the objective to proceed to an analysis of the right to life during the historic succession of Brazilian Constitutions that appeared during the Republican period. Through a historical and dogmatic study, aims to investigate the development of the constitutional protection of human life during successive moments of national history, understanding it in its temporal context and establishing distinctions and interrelations, clarifying the normative scope of the right to life constitutionally guaranteed in the Federal Constitution of 1988.

\footnotetext{
${ }^{1}$ Professor de Direito Penal e Filosofia do Direito no Centro Universitário do Planalto de Araxá, Araxá/MG. Especialista em Ciências Criminais pela Universidade Federal de Uberlândia, Mestre em Direito Público pela Universidade de Franca, Doutor em Eficácia do Direito pela Pontifícia Universidade Católica de São Paulo. http://lattes.cnpq.br/9391697498975556
} 
Keywords: Right to life, Rights concerning to life, Right to personal safety, Republican Constitutions.

\section{INTRODUÇÃO}

A necessidade de desbravar as incertezas que cercam as questões biojurídicas e biopolíticas relacionadas com a vida humana, ainda que evidente, redunda em problema particularmente sensível. Uma vez que caráter primordial da proteção da vida humana é facilmente percebido como evidente pela sociedade nota-se acaloradas e apaixonadas discussões sobre o tema. Tais debates, que não raro misturam elementos morais, ideológicos e religiosos, influenciam, limitam e condicionam a investigação jurídica.

A sensibilidade social relacionada à vida humana é especialmente evidente quando considerados grandes temas que dominam o debate nacional. As questões relacionadas à pesquisa com células-tronco, às intermináveis discussões sobre o aborto e às implicações jurídicas dos diagnósticos de anencefalia e de morte cerebral são justamente aqueles problemas relacionados à vida humana nos quais bem podem se reconhecer a qualidade de hard cases $^{2}$. São tais problemas que testam as fronteiras entre as liberdades individuais e os interesses sociais e/ou estatais. São também estes nos quais é testada a precisão do âmbito de proteção constitucional do ser humano, em especial, considerando o princípio da dignidade da pessoa humana.

Conforme ponderado, apesar de impossível negar a necessidade da discussão jurídica sobre tais temas, uma pergunta fundamental parece esquecida ou relegada à insignificância. Considerada um dado intuitivamente evidente, a definição de vida humana para o Direito resta abandonada e esse abandono não ocorre sem graves consequências. Disso torna-se imprescindível uma investigação profunda do que é isso, o direito à vida, assegurado pela Constituição Federal de 1988, revisitando as Constituições predecessoras e utilizando o estudo histórico para compreender o atual estado da proteção constitucional dispensada à vida humana.

\footnotetext{
${ }^{2}$ Sobre a importância dos casos-limites para a investigação jurídica: "São os chamados hard cases, as questões mais tormentosas, aquelas que terminam sendo examinadas no exercício da jurisdição constitucional, as quais não se resolve satisfatoriamente com o emprego apenas de regras jurídicas, mas demandam o recurso aos princípios, para que sejam solucionadas em sintonia com o fundamento constitucional da ordem jurídica" (GUERRA FILHO, 2009, p. 64).
} 
Essa imperativa necessidade conceitual - que não somente esclareça os contornos essenciais da vida humana protegida pelo Direito, mas que também exerça função limitadora da ingerência do Estado e da sociedade na esfera da autodeterminação individual - é capital para evitar que o Direito seja instrumentalizado para satisfazer interesses de grupos sociais que através do Estado intentam impor sobre a coletividade suas específicas crenças religiosas, morais ou ideológicas. Isso se dá uma vez que o "principal pressuposto metodológico de uma teoria geral do garantismo reside [na separação] entre direito e moral, [...]" (FERRAJOLI, 2000, p. 686).

A clarificação conceitual da vida humana para o Direito, portanto, é condição necessária para proteger o próprio fundamento antropológico dos direitos fundamentais.

\section{A PROTEÇÃO DA VIDA HUMANA NA CONSTITUIÇÃO DE 1891}

Analisando a sucessão histórica das Constituições brasileiras, especialmente no que se refere ao direito à vida, é nota-se que, até a Constituição dos Estados Unidos do Brasil, de 18 de setembro de 1946, não é de se identificar a presença de um dispositivo constitucional no qual seja possível reconhecer uma expressa menção ao direito fundamental à vida.

Segundo a hipótese levantada por Gisele Mendes de CARVALHO (2001), a ausência de um expresso reconhecimento do direito à vida poderia ser explicada pela percepção, naquele momento histórico, de que a vida humana, compreendida como um fato natural, não careceria de licença ou garantia jurídica para que se apresentasse como certa e existente. Nesses termos e segundo tal hipótese, não seria o caso de garantir a vida em si, pois ela existiria independentemente de qualquer direito juridicamente estabelecido. Tratar-se-ia, com acerto, de, reconhecendo tal existência natural, atribuir direitos e garantias ao ser humano de forma a protegê-lo naqueles aspectos biográficos decorrentes da personalidade. Sendo acertada tal hipótese, a vida humana seria considerada, não como um direito, mas, como um fato natural que, uma vez presente, toma-se como pré-condição para o gozo de direitos civis e políticos. 
Noutro sentido, cumpre destacar a hipótese apresentada por Aristides Augusto MILTON (1898). Segundo o autor, a proteção da vida, apesar de não disposta de forma expressa no art. 72 do texto constitucional de $1891^{3}$, poderia ser aduzida como um dos aspectos fundamentais do direito à segurança individual ${ }^{4}$. Dando seguimento a esta linha de interpretação, a vida estaria inserida no âmbito de valores constitucionalmente assegurados, ainda que indiretamente, de modo que o direito à segurança individual poderia e deveria ser compreendido como suficientemente amplo para abarcar a inviolabilidade do direito à vida, assim como da liberdade e de todos os aspectos inerentes ao exercício das faculdades naturais e inerentes à individualidade.

Nos termos da Carta Magna de 1891 e através da proteção da segurança individual, restariam outros direitos - especialmente o direito à vida - amparados sob o domo de tal dispositivo, sendo, por conseguinte, protegidos de qualquer afronta fundada na arbitrariedade humana e, assim, constituindo-se em posições jus fundamentais que não encontrariam limites senão face restrições derivadas da legalidade, do devido processo legal e da tensão entre direitos fundamentais.

Essa concepção de proteção da vida inserida no contexto da segurança individual conecta-se com o princípio da legalidade e do devido processo legal, dispostos respectivamente no art. $72, \S 1^{\circ}$ e $\S 15$ do texto constitucional de 1891, possibilitando o reconhecimento tácito da inviolabilidade da vida humana. Corroborando tal entendimento, é ainda de se destacar o art. 72, § 21, da Constituição de 1891, que abole a pena de morte, reservando sua aplicação somente a um conjunto particular de crimes praticados durante tempo de guerra, excepcionalidade ainda observada no texto constitucional de 1988. Ou seja, o Estado somente poderia tomar a vida de um daqueles submetidos ao seu poder soberano em particulares situações expressamente previstas no texto constitucional e,

\footnotetext{
${ }^{3}$ Redação do dispositivo constitucional: “Art. 72 - A Constituição assegura a brasileiros e a estrangeiros residentes no País a inviolabilidade dos direitos concernentes à liberdade, à segurança individual e à propriedade, nos termos seguintes: [...]".

4 Neste sentido: "Quanto à segurança, devemos considerá-la como a garantia real e effectiva, quer da liberdade, quer dos outros direitos naturaes. Della até se pôde dizer - que é o primeiro sentimento do homem, tanto quanto um dos instinctos mais aguçados de todos os animaes. Pois que resolve-se na defesa de si mesmo, na conservação da existência individual, no direito supremo de viver e não sofrer. Quimper ensina - que a segurança consiste no gozo legal, e não interrompido, da vida e de tudo que a ella se refere, inclusive a reputação. Consequentemente, no estado social - é o direito que o homem tem de ser protegido pelas leis em sua vida, propriedade, saúde e honra, assim como em todos os outros seus bens; de não ficar sujeito senão à benfazeja acção da lei, mas de seus executores legítimos ; de estar ao abrigo de todo arbítrio, e superior a quaisquer violências também.” (MILTON, 1898, p. 371).
} 
ainda assim, em estrita obediência ao devido processo legal. Nestes termos, a hipótese de que o direito à vida está inserido no contexto mais amplo do direito à segurança individual parece ser mais adequado do que a hipótese da vida enquanto fato natural.

A análise sistemática dos preceitos constitucionais da Carta Política de 1891 permite afirmar que, apesar de não disposta expressamente, a proteção da vida poderia, naquela Constituição, ser contemplada como uma posição jus fundamental decorrente do expressamente reconhecido direito à segurança pessoal. Neste sentido, a inviolabilidade da sua existência natural poderia ser sustentada contra ataques de particulares e, mesmo, estatais, uma vez que o Estado não poderia, em obediência à legalidade e ao devido processo legal, determinar, juridicamente, o extermínio do indivíduo por meio da pena de morte salvo, evidentemente, naqueles casos de guerra declarada.

\section{A PROTEÇÃO DA VIDA HUMANA NA CONSTITUIÇÃO DE 1934}

A Carta Política de 1934 continua sem uma expressa indicação da inviolabilidade do direito à vida ainda que, entretanto, apresentasse uma evidente inovação ao incluir no rol de posições jus fundamentais o direito à subsistência .

A inserção do direito à subsistência, indiscutivelmente, amplia a proteção da vida ao reconhecer a necessidade de garantir o direito a um mínimo de condições indispensáveis ao sustento do ser humano.

É, então, de se afirmar que, face os dispositivos da Constituição de 1934, não somente a inviolabilidade da vida humana era garantida inserida ainda sob o manto da proteção à segurança individual -, mas, a ela, somou-se o direito a um padrão básico de qualidade de vida. Tal entendimento é facilmente referendado pela inteligência do art. $115^{6}$ do texto constitucional de 1934 que indicava como um dos objetivos

\footnotetext{
5 Redação do dispositivo constitucional: “Art. 113 - A Constituição assegura a brasileiros e a estrangeiros residentes no País a inviolabilidade dos direitos concernentes à liberdade, à subsistência, à segurança individual e à propriedade, nos termos seguintes: [...]".

${ }^{6}$ Redação do dispositivo constitucional: "Art. 115 - A ordem econômica deve ser organizada conforme os princípios da Justiça e as necessidades da vida nacional, de modo que possibilite a todos existência digna. Dentro desses limites, é garantida a liberdade econômica".
} 
primordiais da outrora Ordem Econômica a garantia de uma existência digna para todos.

A adição do direito à subsistência e doutros inseridos no Capítulo da Ordem Econômica e Social ${ }^{7}$ podem ser compreendidos à luz do impacto inspirador da Constituição de México e da Constituição de Weimar ${ }^{8}$ e do surgimento de uma nova categoria de direitos constitucionais designados como de segunda dimensão ou geração ${ }^{9}$.

Inaugura-se com o advento da Constituição de 1934, uma nova dimensão de proteção jurídica da vida humana, ampliando o direito à vida para além da inviolabilidade da existência natural do indivíduo, explicitando, ainda que de forma programática ${ }^{10}$, a necessidade de um direito social que estabelecesse e garantisse um padrão mínimo de qualidade de vida relacionada ao direito de subsistência que, inclusive,

\footnotetext{
${ }^{7}$ Sobre a Constituição de 1934: "Ao lado da clássica declaração de direitos e garantidas individuais, inscreveu um título sobre a ordem econômica e social e outro sobre a família, a educação e a cultura, com normas quase todas programáticas, sob a influência da Constituição alemã de Weimar" (SILVA, 2006, p. 82).

${ }^{8}$ Sobre os direitos de segunda dimensão: "A recepção constitucional destas novas tendências da Declaração dos Direitos Individuais, para conferir ao Estado a posição de prestador de benefícios, verificou-se em duas Constituições do mundo ocidental, que se distinguem pelas peculiaridades de cada uma, mas que se identificam nas circunstâncias extraordinárias que precederam sua eclosão. Trata-se da Constituição Política dos Estados Unidos Mexicanos, de 5 de fevereiro de 1917, produto da revolução mexicana, votada pelo Congresso Constituinte, reunido no Teatro da República, na cidade de Querétaro, documento que os mexicanos consideram a Primeira Constituição Política e Social do Mundo. E da Constituição da República Alemã, de 11 de agosto de 1919, aprovada pela Assembleia Constituinte, reunida na cidade de Weimar, pouco depois da explosão revolucionária que se seguiu à derrota militar da Alemanha, à abdicação do Kaiser Guilherme II e à supressão da Monarquia" (HORTA, 1995, p. 247).

${ }^{9}$ Conforme ensinamento de Willis Santiago GUERRA FILHO aponta-se uma melhor adequação do termo "dimensão" ao revés de "geração" para designar a formação sucessiva dos direitos fundamentais. Neste sentido: "Que ao invés de 'gerações" é melhor falar em 'dimensões de direitos fundamentais', neste contexto, não se justifica apenas pelo preciosismo de que as gerações anteriores não desaparecem com o surgimento das mais novas. Mais importante é que os direitos 'gestados' em uma geração, quando aparecem na ordem jurídica que já traz direitos da geração sucessiva, assumem outra dimensão, pois os direitos de geração mais recente tornam-se um pressuposto para entendê-los de forma mais adequada - e, consequentemente, também para realizá-los. Assim, por exemplo, o direito individual à propriedade, num contexto em que se reconhece a segunda dimensão dos direitos fundamentais, só pode ser exercido observando-se sua função social, e com o aparecimento da terceira geração, observando-se igualmente sua função ambiental" $(2009$, p. 43).

${ }^{10}$ Do caráter programático dos designados direitos de segunda dimensão (geração): "De juridicidade questionada nesta fase [primeira metade do século XX], foram eles [direitos constitucionais de segunda geração] remetidos à chamada esfera programática, em virtude de não conterem para a sua concretização aquelas garantias habitualmente ministradas pelos instrumentos processuais de proteção aos direitos da liberdade. Atravessam, a seguir, uma crise de observância e execução, cujo fim parece estar perto, desde que as recentes Constituições, inclusive a do Brasil, formulam o preceito da aplicabilidade imediata dos direitos fundamentais" (BONAVIDES, 2011, p. 518).
} 
constituía-se em um dos objetivos fundamentais da organização da ordem econômica e social.

Outros fatos históricos se seguem, e a política torna-se claramente influenciada pelo avanço das ideologias fascistas na Itália de Mussolini e na Alemanha de Hitler. Getúlio Vargas, alçado ao poder no contexto da Revolução de 1930, é eleito presidente em 17 de julho de 1934, colocando fim ao período do Governo Provisório, e anuncia o início de um Governo Constitucional com um mandato de quatro anos legitimado por uma eleição indireta na qual Getúlio Vargas recebeu a maioria dos votos dos deputados da Assembleia Constituinte. O recrudescimento da verve autoritária de Getúlio Vargas faz-se culminante na ocasião do golpe de estado que marca o advento do Estado Novo em 10 de novembro de 1937. É justamente neste ambiente golpista e claramente autoritário que Vargas dissolve a Assembleia Constituinte e outorga, no mesmo dia do golpe, aquela Constituição que ficaria conhecida como "Polaca", em razão das flagrantes influências da Carta autoritária polonesa.

\section{4 \\ A PROTEÇÃO DA VIDA HUMANA NA CONSTITUIÇÃO DE 1937.}

Como sempre em regimes autoritários e totalitários, a proteção da vida experimenta um grave revés. Apesar do art. 122 da Constituição de 1937 repetir textualmente aquela garantia à segurança individual constante em textos constitucionais anteriores, resta patente que os direitos fundamentais foram severamente mitigados. No preâmbulo da "Polaca" a relativização das posições jus fundamentais é evidente e fundamentado sob o pretexto, expressamente enunciado, de que sob a égide das "instituições anteriores, não dispunha, o Estado de meios normais de preservação e de defesa da paz, da segurança e do bem-estar do povo; [...]".

Sob a tradicional escusa, típica de governos autoritários e totalitários, de que seria necessário o cerceamento da proteção constitucional dos direitos e garantias individuais para satisfação de necessidades decorrentes de políticas de defesa da segurança e do bemestar do povo, é observada uma tirânica violação dos direitos humanos.

Resta inconteste, pelo exame do texto constitucional de 1937, o evidente retrocesso na proteção dos direitos individuais, especialmente, no que se refere aos elementos constitucionais relacionados com a proteção da 
segurança individual e, por consequência, da proteção da própria vida humana ${ }^{11}$. Verifica-se que, apesar de reconhecer expressamente os direitos de liberdade, segurança e propriedade do indivíduo, a Carta outorgada em 1937, destacava que tais direitos deveriam ser compreendidos, sempre, como limitados e relativizados quando opostos a interesses públicos. Esta proposição é facilmente confirmada pelas restrições expressas que foram gravadas no próprio art. 122 da Polaca que dispunha sobre os direitos e garantias individuais (SILVA, 2006, p. 83).

A mitigação da proteção constitucional do direito à vida é ainda mais evidente quando analisado, especificamente, o disposto no art. 122, parágrafo 13 da Carta de $1937^{12}$, que pugnava pela aplicação da pena de morte para além dos casos previstos na legislação militar quando de situação de estado de guerra. Ampliando, assim, as possibilidades da pena capital para vários delitos que atentassem contra a segurança nacional e, também, para situações de homicídio qualificado por motivo fútil ou com

\footnotetext{
${ }^{11}$ Ainda sobre a Constituição de 1937: "Era de se esperar que a Constituição de 1937 criasse restrições aos direitos individuais e às suas garantias. Sua origem depunha contra vários princípios de obrigatória inclusão dos Textos Constitucionais regradores do Regime Democrático, por isso nela não foram albergados os princípios da legalidade, da irretroatividade da lei nem tampouco o Mandado de Segurança orgulhosamente inaugurado pela Carta Política de 1934. Em lugar deles reapareceu a pena de morte para os crimes políticos e para os homicídios cometidos por motivo fútil e com extremos de perversidade. O direito de manifestação de pensamento foi limitado através da censura prévia da imprensa, teatro, cinema e radiofusão, sendo facultado à autoridade competente proibir a circulação, a difusão e a representação, nenhum jornal podia, ainda recusar a inserção de comunicados do governo, nas dimensões taxadas pela lei; ao diretor responsável seria imposta pena de prisão e à empresa aplicada a pena pecuniária; as máquinas e os utensílios tipográficos utilizados na impressão do jornal constituíam garantia do pagamento da multa, reparação ou indenização, e das despesas com o processo nas condenações pronunciadas por delito de imprensa. Tudo isso, como prescrito no artigo 15 da Constituição Polaca, em garantia da paz, da ordem e da Segurança Pública" (ALVES apud BASTOS; MARTINS, 1988, p. 310).

${ }^{12}$ Redação do dispositivo constitucional: “Art. 122 [...]:[...]13) Não haverá penas corpóreas perpétuas As penas estabelecidas ou agravadas na lei nova não se aplicam aos fatos anteriores. Além dos casos previstos na legislação militar para o tempo de guerra, a pena de morte será aplicada nos seguintes crimes: a) tentar submeter o território da Nação ou parte dele à soberania de Estado estrangeiro; b) atentar, com auxílio ou subsídio de Estado estrangeiro ou organização de caráter internacional, contra a unidade da Nação, procurando desmembrar o território sujeito à sua soberania; c) tentar por meio de movimento armado o desmembramento do território nacional, desde que para reprimi-lo se torne necessário proceder a operações de guerra; d) tentar, com auxílio ou subsídio de Estado estrangeiro ou organização de caráter internacional, a mudança da ordem política ou social estabelecida na Constituição; e) tentar subverter por meios violentos a ordem política e social, com o fim de apoderarse do Estado para o estabelecimento da ditadura de uma classe social; f) a insurreição armada contra os Poderes do Estado, assim considerada ainda que as armas se encontrem em depósito; g) praticar atos destinados a provocar a guerra civil, se esta sobrevém em virtude deles; h) atentar contra a segurança do Estado praticando devastação, saque, incêndio, depredação ou quaisquer atos destinados a suscitar terror; i) atentar contra a vida, a incolumidade ou a liberdade do Presidente da República; j) o homicídio cometido por motivo fútil ou com extremos de perversidade".
} 
extrema perversidade, mesmo que tais crimes fossem perpetrados em tempos de paz.

\section{A PROTEÇÃO DA VIDA HUMANA NA CONSTITUIÇÃO DE 1946.}

Inserida no contexto histórico do pós-guerra e da derrocada no nacional-socialismo alemão e do fascismo, a Carta Política de 1946, em um claro rompimento com as inspirações autoritárias da predecessora, afirmava-se mais democrática em várias questões relacionadas com direitos civis. Esse fato é facilmente comprovado por dispositivos constitucionais que ampliaram a liberdade de criação de partidos políticos, ressalvadas, entretanto, as hipóteses, nas quais a tal associação ou partido político estivesse organizado com vistas a finalidades expressamente vedadas nos termos do art. 141, § 13 da referida Carta Política, a saber, nesses termos "é vedada a organização, o registro ou o funcionamento de qualquer Partido Político ou associação, cujo programa ou ação contrarie o regime democrático, baseado na pluralidade dos Partidos e na garantia dos direitos fundamentais do homem". Esse particular dispositivo da Carta Política de 1946 é deveras esclarecedor sobre a importância dos direitos humanos nos primeiros anos após o sombrio período da II Guerra Mundial.

Os terrores testemunhados durante aquele período daquele conflito, que superaram em método e escala quaisquer outros na história da humanidade, serviram para triste demonstração da relação necessária entre a democracia e os direitos fundamentais do homem ${ }^{13}$.

A degeneração da democracia e a ascensão dos regimes totalitários - notadamente, na Alemanha, Itália e União das Repúblicas Socialistas Soviéticas - somente foram possíveis em face da crise do capitalismo e do liberalismo político. Os sistemas de proteção dos direitos humanos, de forma geral, falharam fragorosamente, inclusive no Brasil, e permitiram a instrumentalização do Estado a serviço de ideologias totalitárias, da demagogia e do culto à personalidade de terríveis tiranos. Nesse contexto, o art. 141, $§ 13$ da Constituição de 1946 é particularmente

\footnotetext{
${ }^{13}$ Sobre a relação entre os direitos fundamentais e a Democracia: "Os direitos fundamentais tornamse, assim, o que há de mais importante a ser consagrado na Constituição de um Estado Democrático, com sua multidimensionalidade, enquanto os direitos de liberdade, direitos a prestações (os direitos sociais), direitos à participação na formação da vontade política estatal, direitos de natureza processual, etc." (GUERRA FILHO, 1997, p. 71).
} 
emblemático, pois enuncia a compreensão da importante lição aprendida através dos horrores decorrentes da ascensão e queda dos regimes totalitários nos vinte anos anteriores, pois afirma que democracia está indissociavelmente relacionada à garantia dos direitos fundamentais do homem.

Os direitos e garantias individuais, segundo o art. 141, § 13 da Carta Política de 1946, seriam elevados à condição de fundamento antropológico da própria democracia, reconhecendo que essa não pode ser construída sem a elaboração de um sistema efetivo de tutela daqueles considerados os mais elementares direitos humanos e sem o reconhecimento da dignidade inerente ao ser humano ${ }^{14}$.

Partindo de tal premissa e, especialmente, no tocante à proteção da vida humana, observa-se que o caput do art. 141 da Constituição de 1946 inova em relação aos textos constitucionais anteriores. A tutela constitucional da vida humana, antes inserida no contexto da segurança individual, passa a ser considerada como digna de proteção expressa e autônoma, nos seguintes termos: "A Constituição assegura aos brasileiros e aos estrangeiros residentes no País a inviolabilidade dos direitos concernentes à vida, à liberdade, a segurança individual e à propriedade, nos termos seguintes: $[\ldots]$ ".

A proteção dos direitos concernentes à vida não constitui em única inovação apresentada na Constituição de 1946. Em relação aos limites da inviolabilidade da vida, é de se destacar o art. 141, § 31 da mesma Carta, que determinava uma redução das possibilidades de pena de morte em relação à Constituição de 1937. Restringia a pena capital aos casos expressamente previstos na "legislação militar em tempo de guerra com país estrangeiro".

Digna, ainda, de nota a adição da garantia de prestação jurisdicional no caso de lesões de direitos individuais, nos termos do disposto do $\S 4^{\circ}$ do art. 141 da Carta Magna de $1946^{15}$.

\footnotetext{
${ }^{14}$ Sobre a democracia e sua relação com os direitos fundamentais e a dignidade da pessoa humana: "A democracia, por seu turno, representa o reconhecimento de igual dignidade em todas as pessoas, individualmente, a ser acatada no convívio social. Essa dignidade não pode ser sacrificada em nome da segurança, na hipótese de um confronto entre os dois valores, o que pode ocorrer com frequência, embora a garantia de segurança seja essencial para haver respeito à dignidade humana" (GUERRA, 2009a, p. 155).

${ }^{15}$ Ainda sobre a Constituição de 1946: "Em matéria de direitos individuais, retoma-se o rol já constante da Constituição de 1934, mas agregam-se alguns dispositivos de muita importância: é o caso do $\S 4^{\circ}$ do art. 141, que assegura o acesso incondicional ao Poder Judiciário ao afirmar que nenhuma lesão de direito individual poderá ser subtraída de sua apreciação. Trata-se, sem dúvida, de garantia de grande
} 
Porém, ainda que seja possível reconhecer um evidente avanço na tutela constitucional dos direitos e garantias individuais em relação ao texto constitucional de 1937, tais avanços em matéria de direitos humanos, em verdade, eram, pouco mais, do que um retorno às situações anteriores à Constituição Polaca.

Como se afirma o clichê, a história continuamente se repete; o avanço democrático observado na Constituição de 1946 não durou muito tempo, e um novo e grave retrocesso em relação à proteção constitucional dos direitos e garantias individuais fez-se mais uma vez presente na história brasileira quando do dia $1^{\circ}$ de abril de 1964, um Comando, dito, "Revolucionário", instaurou uma ditadura militar que duraria mais de duas décadas que se fazem lembrar como um período sombrio que mancharia para sempre a memória nacional com sistemáticas supressões de liberdades individuais e direitos políticos, assim como a instrumentalização do aparato estatal para práticas de desaparecimentos, torturas e assassinatos políticos.

Já nas primeiras alvoradas do governo militar golpista, nota-se o início de uma sequência de atos institucionais e outros complementares que serviriam à instauração de um estado de exceção que progressivamente esmagou inúmeros direitos considerados fundamentais para qualquer Estado que queira para si a qualidade de democrático de Direito.

Os direitos políticos foram, então, sistematicamente limitados, suspensos ou suprimidos. A discordância era confundida com traição; a liberdade de expressão era vigiada e mitigada, sendo que a liberdade de imprensa foi limada por meio de censura prévia ${ }^{16}$.

É nesse contexto, de estado de exceção e de completa crise de legitimidade, que se verificou a promulgação da Constituição de 1967, precisamente no dia 24 de janeiro de 1967 durante o governo do, então presidente, marechal Arthur da Costa e Silva.

alcance que compõe um dos pilares sobre os quais se erige o estado de direito" (BASTOS; MARTINS,1988, p. 315).

${ }^{16}$ Nas palavras de Carlos Medeiros Silva, Ministro da Justiça quando dos idos de 1967: "o estado de sítio ficou estruturado tendo em vista o disposto nos Atos Institucionais $n^{\circ} 1$ e 2 e que a sua decretação importa, desde logo, na suspensão de certas garantias constitucionais [...]” (BONAVIDES, 1991, p. 443). 


\section{A PROTEÇÃO DA VIDA HUMANA NA CONSTITUIÇÃO DE 1967}

Pode parecer estranho notar que, em relação aos direitos e garantias individuais, pouco do texto da Carta Política (1946) anterior foi modificado na redação da Constituição de 1967. Isso fica patente pela leitura do art. 150, caput, do referido diploma constitucional. "A inviolabilidade dos direitos concernentes à vida, à liberdade, à segurança e à propriedade", apesar de textualmente garantida, foi limitada por uma série de dispositivos - encontrados tanto na Constituição, quanto na legislação ordinária - que deixava claro o retrocesso em matéria de direitos humanos e permitia identificar a evidente influência dos ditames encontrados na Constituição "Polaca" de $19377^{17}$ neste texto de 1967.

Tais limitações de caráter claramente antidemocrático materializaram na Carta de 1967 a prevalência da proteção da "segurança nacional" sobre as garantias constitucionais, irradiando-se ${ }^{18}$ por todo o sistema jurídico brasileiro que, contaminado por uma patológica influência autoritária e golpista, pode ser considerado como formalmente ilegítimo e materialmente injusto. $\mathrm{O}$ caráter injusto daquela ordem jurídica pode ser facilmente comprovado pela histórica observação de flagrantes e recorrentes atentados contra os direitos fundamentais que foram perpetrados pelo Estado brasileiro durante os chamados "anos de chumbo".

A verve autoritária e a obsessão pela segurança nacional presentes na Carta de 1967 são visíveis, de pronto, pela análise do art. 155, $\S 11$, que ampliou os casos de pena de morte para além dos crimes militares em caso de guerra declarada de modo a abarcar, também, toda uma gama de crimes políticos praticados por agentes "subversivos", como eram designados pelo governo militar ${ }^{19}$.

\footnotetext{
${ }^{17}$ Sobre a influência Polaca na Carta Política de 1967: "Sofreu ela [Constituição de 1967] poderosa influência da Carta Política de 1937, cujas características básicas assimilou. Preocupou-se fundamentalmente com a segurança nacional. Deu mais poderes à União e ao Presidente da República. [...]. Reduziu a autonomia individual, permitindo a suspensão de direitos e garantias constitucionais, no que se revela mais autoritária do que as anteriores, salvo a de 1937" (SILVA, 2006, p. 97).

${ }^{18}$ Sobre a tese da irradiação: "La tesis de la irradiación dice que la falta de carácter jurídico de las normas substantivas básicas de un sistema jurídico trae consigo la falta de carácter jurídico de todas as normas típicas del sistema y, en este sentido, ejerce una irradiación sobre ellas" (ALEXY, 2004, p. 69) ${ }^{19}$ Segue-se a redação do referido dispositivo constitucional da Carta de 1967: “Art. 155. [...]:§ 11 - Não haverá pena de morte, de prisão perpétua, de banimento, ou confisco, salvo nos casos de guerra externa psicológica adversa, ou revolucionária ou subversiva nos termos que a lei determinar. Esta disporá também, sobre o perdimento de bens por danos causados ao Erário, ou no caso de enriquecimento ilícito no exercício de cargo, função ou emprego na Administração Pública, Direta ou Indireta".
} 
Porém, mesmo todo o retrocesso em matéria de direitos humanos, conforme identificado pela análise da Constituição de 1967, não foi suficiente para satisfazer o imperativo da segurança nacional.

O Ato Institucional n. 5, para todos os efeitos, viria a substituir a Carta Política de 1967, fundando assim uma nova ordem jurídica na qual os poderes acabaram por concentrar-se nas mãos do Presidente da República. Tal ato institucional, de tão intenso em seu autoritarismo que reconhecia situações nas quais seria admissível a suspensão do Habeas $\operatorname{Corpus}^{20}$. Aquela histórica crise de legitimidade, ainda que patente, não foi desafiada, salvo honrosas exceções, pela comunidade jurídica brasileira.

A Junta Militar, no uso dos poderes que lhe foram atribuídos pelo Ato Institucional n. 5, apresentou a Emenda Constitucional n. 1 (1969) que substituiu o já autoritário texto de 1967. Seguidas emendas constitucionais sucederam-se nos anos seguintes, sendo que uma dessas alterações, particularmente digna de nota, apresentou-se na emenda do art. 155, $\S 11^{21}$, que restringiu novamente a aplicação da pena de morte aos casos previstos na legislação militar e nos tempos de guerra declarada. Tal alteração do texto constitucional foi operada pela Emenda Constitucional n. 11 de 1978, quando a ditadura militar brasileira mostrava evidentes sinais de desgaste e já se apresentava no horizonte o fortalecimento dos movimentos pela democracia e as conversações iniciais pela Lei da Anistia. Tal emenda constitucional, infelizmente, não veio em tempo devido para evitar o fato historicamente incontestável, de que vários casos de assassinatos, torturas e desaparecimentos, patrocinados por militares e civis acobertados pelo Estado, tenham encontrado tempo durante os designados "anos de chumbo" da história brasileira.

A Emenda Constitucional n. 26, em 27 de novembro de 1985, que convocou uma Assembleia Nacional Constituinte, é verdadeiro ato

\footnotetext{
${ }^{20}$ Sobre as disposições do Ato Institucional n. 5: "O Ato [Institucional n. 5) também permitia medidas extremamente drásticas, consistentes na cassação de mandatos de parlamentares, assim como na possibilidade de suspender os direitos políticos por dez anos de qualquer pessoa. Garantias próprias da magistratura como vitaliciedade e inamobilidade estavam suspensas, assim como as garantias do funcionalismo em geral, tal como a estabilidade. Tudo isto ficava suspenso pelo Ato Institucional n. 5, visto que com fundamento nele esses direitos poderiam ser afastados. O seu autoritarismo era tão grande que chegava ao ponto de suspender o Habeas Corpus, no caso de crimes políticos contra a segurança nacional, a ordem econômica e social e a economia popular" (BASTOS; MARTINS:1988, p. 323).

${ }^{21}$ Nos termos da redação do referido dispositivo constitucional: “Art. 155. [...]:[...]. § 11 - Não haverá pena de morte, de prisão perpétua, nem de banimento. Quanto à pena de morte, fica ressalvada a legislação penal aplicável em caso de guerra externa. A lei disporá sobre o perdimento de bens por danos causados ao erário ou no caso de enriquecimento no exercício de função pública".
} 
político $^{22}$ que marca o ápice da popularização e do fortalecimento dos movimentos pelo retorno da democracia no Brasil, bem como a inevitabilidade de um retorno à normalidade e legitimidade jurídica depois de mais de duas décadas de um governo golpista e autoritário. Ainda que a transição tenha sido intermediada por um governo eleito indiretamente naquele mesmo ano, serviu de prenúncio para a designada "Constituição Cidadã" de 1988 e para as eleições diretas que teriam seu momento em 1989.

\section{A PROTEÇÃO DA VIDA HUMANA NA CONSTITUIÇÃO DE 1988.}

A histórica caminhada até o momento da promulgação da Constituição Federal de 1988 é marcada por avanços e retrocessos na proteção dos direitos e garantias fundamentais do ser humano e, especialmente, como não poderia deixar de ser, no que se refere ao direito à vida.

As inovações realizadas pelo constituinte originário da Carta Política de 1988 marcam, não somente, a pedra angular sobre a qual a democracia brasileira foi erigida, mas também, informam uma nova visão de direitos e garantias individuais e sociais e, especialmente, da proteção da vida humana em seus vários aspectos.

Sob o véu da Constituição de 1988, dita "Constituição Cidadã", os direitos e garantias fundamentais passam a ser compreendidos, não somente, como direitos públicos subjetivos do indivíduo, mas também como elementos de ordem objetiva ${ }^{23}$ e elevados, assim, ao patamar de base

\footnotetext{
${ }^{22}$ Sobre o caráter ato constituinte originário da Emenda n. 26, de 27 de novembro de 1985: "Em verdade, a EC n. 26 de 27.11.85, ao convocar a Assembleia Nacional Constituinte para elaborar Constituição nova que substituiria a que estava em vigor, por certo não tem natureza de emenda constitucional, pois esta tem precisamente o sentido de manter a Constituição emendada. Se visa destruir esta, não pode ser tida como emenda, mas como ato político" (SILVA, 2006, p. 87).

${ }^{23}$ Sobre direitos e garantias individuais como elementos constitucionais de ordem objetiva: "Como elementos da ordem objetiva, determinante de status, limitadora de status e asseguradora de status, que inserem o particular na coletividade, os direitos fundamentais constituem bases da ordem jurídica da coletividade. Nisso existe, para as camadas de significado individuais dos direitos fundamentais como direitos subjetivos, uma relação de complemento e fortalecimento recíprocos; esta exclui separar o significado de direitos fundamentais como princípios objetivos, do significado primitivo e fundamental, como direitos do homem e do cidadão. Ao significado dos direitos fundamentais como direitos de defesa subjetivos do particular corresponde seu significado jurídico-objetivo como determinações de competências negativas para os poderes estatais. Sem dúvida, é a sua função proteger
} 
estrutural da configuração jurídica e política brasileira. O Estado, sob tal égide, passa a tomar para si, como missão primordial, a guarda, a proteção e a promoção dos direitos humanos ${ }^{24}$.

Tal compreensão de direitos humanos pode ser desprendida da análise de vários elementos textuais da Carta Política de 1988, a começar pelo próprio preâmbulo, que, mesmo considerando a ausência de caráter dispositivo de suas linhas, permite reconhecer a histórica finalidade do constituinte quando da redação. $\mathrm{O}$ constituinte originário declara que a República Federativa do Brasil, assim criada como Estado Democrático, tem para si a missão, nos termos do Preâmbulo da Constituição Federal, de:

[...] assegurar o exercício dos direitos sociais e individuais, a liberdade, a segurança, o bem-estar, o desenvolvimento, a igualdade e a justiça como valores supremos de uma sociedade fraterna, pluralista e sem preconceitos, fundada na harmonia social e comprometida, na ordem interna e internacional, com a solução pacífica das controvérsias, [...].

O reconhecimento do caráter objetivo dos direitos humanos determina, consequentemente, que o status individual da pessoa inserida na ordem social é um elemento limitador e organizador dos poderes estatais $^{25}$.

A atual Carta Política determina uma série de posições fundamentais da ordem constitucional que permitem o reconhecimento de princípios sob os quais o Estado deverá exercer sua missão, dentre eles, destacando-se o art. $1^{\text {o }}$, III, da Constituição Federal que impõe como fundamento da República Federativa do Brasil a dignidade da pessoa humana.

\footnotetext{
os direitos fundamentais, podem eles ser obrigados a concretizar direitos fundamentais, e podem eles ser autorizados a limitar direitos fundamentais; mas o status individual da liberdade e igualdade garantido com essa medida pelos direitos fundamentais está subtraído à sua competência e ele é protegido por essa subtração contra os poderes estatais" (HESSE, 1998, p. 239).

${ }^{24}$ Da natureza objetiva dos direitos fundamentais na ordem constitucional brasileira: "Ganhou alento a percepção de que os direitos fundamentais possuem uma feição objetiva, que não somente obriga o Estado a respeitar os direitos fundamentais, mas que também o força a fazê-los respeitados pelos próprios indivíduos, nas suas relações entre si” (BRANCO; COELHO;MENDES, 2007, p. 265).

${ }^{25}$ Do aspecto subjetivo-objetivo dos direitos fundamentais: "Ao significado dos direitos fundamentais como direitos subjetivos que, por causa de sua atualização, são garantidos, corresponde seu significado jurídico-objetivo como elementos da ordem jurídica total da coletividade, pela qual o status do participante é organizado, delimitado e protegido, que, porém, por sua vez, primeiro pode ganhar realidade quando ela, pela atualização dos direitos fundamentais como direitos subjetivos, é cumprida como vida" (HESSE, 1998, p. 240).
} 
O caráter jurídico-objetivo dos direitos humanos na Carta Política de 1988 é ainda mais evidente quando da análise de seu art. 60, § $4^{\circ}$, IV que dispõe uma expressa limitação ao poder constituinte derivado no sentido de que "não será objeto de deliberação nenhuma proposta de emenda tendente a abolir [...] os direitos e garantias fundamentais" ${ }^{26}$.

\section{CONCLUSÃO}

Em suma, a Constituição Federal de 1988, não somente resgata e amplia os designados direitos humanos previstos nas Cartas Políticas anteriores, mas vai além daquilo que lhe foi historicamente anterior e eleva os direitos humanos, particularmente os individuais e suas concernentes garantias, ao patamar de elementos fundamentais de ordem objetiva, protegidos inclusive contra o poder constituinte derivado. Tudo isso alicerçado no reconhecimento da dignidade da pessoa humana como fundamento de todas as posições jusfundamentais, princípio esse, portanto, determinante na informação de como o Estado deverá configurar suas relações com as pessoas e de como devem relacionar-se os indivíduos entre si no âmbito das relações sociais acobertadas pela ordem jurídica vigente ${ }^{27}$.

Trata-se de considerar que o caráter objetivo dos direitos e garantias fundamentais do indivíduo constitui-se em uma mudança de paradigma, através da qual a ideia de um poder supremo e ilimitado fundado na vontade da maioria é superada por uma configuração de Estado Democrático que se faça garantidor dos direitos individuais contra as

\footnotetext{
${ }^{26}$ Sobre os direitos fundamentais e sua consideração como cláusulas pétreas: "Analisando a questão das chamadas cláusulas pétreas e a possibilidade de controle de constitucionalidade das emendas constitucionais, Gilmar Ferreira Mendes aponta que tais cláusulas de garantia trazem a verdade, um esforço do constituinte para assegurar a integridade da constituição, obstando a que eventuais reformas provoquem a destruição, o enfraquecimento ou impliquem profundas mudança de identidade, pois a constituição contribui para a continuidade da ordem jurídica fundamental, à medida que impede a efetivação do término do Estado Direito democrático sob a forma da legalidade, evitando-se que o constituinte derivado suspenda ou mesmo suprima a própria constituição" (MORAES, 2008, p. 664).

${ }^{27}$ Neste sentido: "os direitos humanos e a Democracia. Ambos podem ser abrangidos por temática mais ampla, de cujo tratamento estamos necessitando mais do que qualquer coisa, especialmente no Brasil pós-Constituição de 1988: o Estado Democrático de Direito. É legítimo esperar que a filosofia do Direito e do Estado explicitem a significação dessa fórmula político-jurídica, com base na qual se deve configurar nosso ordenamento jurídico. A simples leitura de nossa Constituição não deixa dúvida quanto ao papel central que ocupa nessa fórmula a defesa dos direitos fundamentais da pessoa, que seriam uma transposição, no plano do direito positivo, da problemática, comum à jusfilosofia e à filosofia política, em torno dos direitos humanos" (GUERRA FILHO, 2009a, p. 28).
} 
possíveis degenerações demagógicas e totalitárias, como os exemplos históricos do fascismo italiano e o nacional-socialismo alemão ${ }^{28}$.

Os direitos e garantias individuais e sociais passam a ser protegidos de movimentos de contra-revolução social, típicos de momentos de aguda comoção pública ou convulsão social, nos quais a opinião pública torna-se particularmente permeável a argumentos demagógicos e, em regra, reacionários. Afirma-se que o princípio do não retrocesso, ainda que não expressamente disposto, pode ser deduzido desse caráter objetivo dos direitos e garantias individuais e sociais de modo que tais conquistas jurídicas não possam ser revertidas ao sabor das paixões de momento, mesmo que contem com o apoio maciço da população ${ }^{29}$, porque passam a integrar a própria configuração elementar que caracteriza o Estado Democrático de Direito fundado pela Constituição Federal de 1988.

Considerando, portanto, a inescapável remissão de todos os direitos e garantias individuais ao princípio da dignidade da pessoa humana, resta imperativo, para a compreensão do alcance das proteções jusfundamentais, um detido estudo sobre o alicerce dos próprios direitos fundamentais. A dignidade da pessoa humana constitui-se, desta forma, no inescapável ponto de partida para qualquer investigação, pois se faz fundamento antropológico do arcabouço de direitos e proteções fundamentais.

\footnotetext{
${ }^{28}$ Sobre a limitação do poder da maioria como obstáculo à demagogia, autoritarismo e totalitarismo: "También cambió la estructura de la democracia, que ya no consiste en el poder ilimitado del pueblo $\mathrm{y}$, por lo tanto, de la mayoría, en condiciones de degenerar - como mostraron el fascismo y el nazismo - en formas totalitarias. Más bien, ella es ahora un "poder del pueblo" en los límites y con los vínculos impuestos por las constituciones. Por ello, su ejercicio no solo está sujeto a los tradicionales derechos a la vida y de libertad, sino también a los derechos a la supervivencia, que son los derechos a la salud y a la subsistencia y otros derechos sociales constitucionalmente establecidos" (FERRAJOLI in BAIGÚN:2005, p. 640)

${ }^{29}$ Sobre o princípio da proibição de retrocesso: “A ideia aqui expressa também tem sido designada como proibição de «contrarrevolução social» ou da «evolução reaccionária». Com isso quer dizer-se que os direitos sociais e económicos (ex.: direito dos trabalhadores, direito à assistência, direito à educação), uma vez alcançados ou conquistados, passam a constituir, simultaneamente, uma garantia institucional e um direito subjectivo. Desta forma, e independentemente do problema «fáctico» da irreversibilidade das conquistas sociais (existem crises, situações económicas difíceis, recessões económicas), o princípio em análise justifica, pelo menos, a subtracção à livre e oportunística disposição do legislador, da diminuição de direitos adquiridos (ex.: segurança social, subsídio de desemprego, prestações de saúde), em clara violação do princípio da protecção da confiança e da segurança dos cidadãos no âmbito económico, social e cultural" (CANOTILHO, 1993, p. 468-9).
} 


\section{REFERÊNCIAS BIBLIOGRÁFICAS}

BAIGÚN, David et al. Estudios sobre la Justicia Penal: homenaje al Prof. Julio B. J. Maier. Buenos Aires: Del Puerto, 2005.

BASTOS, Celso Ribeiro; MARTINS, Ives Gandra. Comentários à Constituição do Brasil. V. 1. São Paulo: Saraiva, 1988.

BONAVIDES, Paulo. História constitucional do Brasil. 3.e. Rio de Janeiro: Paz e Terra, 1991.

BRANCO, Paulo Gustavo Gonet; COELHO, Inocêncio Mártires; MENDES, Gilmar Ferreira. Curso de direito constitucional. São Paulo: Saraiva, 2007.

CANOTILHO, J. J. Gomes. Direito Constitucional. 6.e. Coimbra: Livraria Almedina, 1993.

CARVALHO, Gisele Mendes de. Aspectos jurídicos-penais da eutanásia. São Paulo: IBCCrim, 2001.

FERRAJOLI, Luigi. Direito e razão: teoria do garantismo penal. São Paulo: Revista dos Tribunais, 2002.

GUERRA FILHO, Willis Santiago. Autopoiese do Direito na sociedade pós-moderna. Porto Alegre: Livraria do Advogado, 1997.

Processo constitucional e direitos fundamentais. 6. e.. São Paulo: SRS, 2009.

Teoria da Ciência Jurídica. 2. e. São Paulo: Saraiva, 2009a.

HESSE, Konrad. Elementos de direito constitucional da República Federal da Alemanha. Sérgio Antônio Fabris: Porto Alegre, 1998.

HORTA, Raul Machado. Estudos de direito constitucional. Belo Horizonte: Del Rey, 1995.

MILTON, Aristides Augusto. A Constituição do Brazil: Notícia histórica, texto e comentário. 2.e. Rio de Janeiro: Imprensa Nacional, 1898.

MORAES, Alexandre de. Direito constitucional. 23.e. São Paulo: Atlas, 2008.

SILVA, José Afonso da. Curso de direito constitucional positivo. 26.e. São Paulo: Malheiros, 2006. 